\title{
Managing glaucoma in developing countries
}

\section{Lidando com o glaucoma em países em desenvolvimento}

Mauro Toledo Leite ${ }^{1}$, Lisandro Massanori Sakata ${ }^{2}$, Felipe Andrade Medeiros ${ }^{1,3}$

\section{HOW BIG IS THE PROBLEM?}

A recent estimate of the number of people affected by glaucoma worldwide suggested that by 2020 there will be approximately 80 million people with the disease, of which 11 million will be bilaterally blind ${ }^{(1)}$. Due to the paucity of information on disease prevalence in Latin America, estimates of prevalence for this region have been derived mostly from studies conducted in Hispanic populations living in the United States ${ }^{(1)}$. These extrapolated prevalence rates are likely to be inaccurate, particularly in Brazil, due to its heterogeneous and highly racially-mixed population.

Very few data are available on the prevalence of glaucoma in the Brazilian population. A recent population based-study conducted in the south of Brazil found an overall glaucoma prevalence of 3.4\% (95\% Cl: $2.5 \%$ to $4.3 \%$ ) in a sample of 1,636 subjects over 40 years of age. Open-angle glaucoma (OAG) was the most common form of the disease with an estimated prevalence of $2.4 \%$, which increased sharply with aging, achieving $4 \%$ in those 60 years of age or older ${ }^{(2)}$. Interestingly, almost $90 \%$ of the glaucoma patients were not aware of their diagnoses, a number that is much higher than estimates of disease awareness previously reported for developed countries, which have been close to $50 \%^{(3-5)}$. As the population in developing countries ages, the number of individuals with glaucoma will increase, likely worsening the socio-economic burden of the disease. According to the United Nations estimation, the number of Brazilians over 60 years old is estimated to grow from approximately 20 million people in 2010 to 64 million in 2050 ${ }^{(6)}$. That would represent an increase from 800,000 people with OAG in 2010 to approximately 2.6 million in 2050.

It is important to emphasize that a study of glaucoma prevalence conducted in the south of Brazil may not be able to fully characterize the burden of the disease in the whole country, due to the highly heterogeneous ethnic composition of the Brazilian population according to the regions of the country. For example, in the study of Sakata et al., 71\% of the examined sample was self-declared as White. Non-Whites tended to show a higher prevalence of OAG and also a higher rate of blindness from the disease compared to Whites, although estimates of prevalence and blindness in non-Whites were largely imprecise due to the small sample size ${ }^{(2)}$. It is likely that the overall numbers on prevalence and burden of the disease would be different had the study been conducted in the northern parts of the country. Population-based epidemiologic studies are essential in order to provide information on the magnitude of the problem so that adequate strategies can be planned to deal with it. Such studies can be very costly and, therefore, support from government agencies or other forms of federal or private support are essential to ensure adequate funding.

\section{DETECTION OF THE DISEASE}

As a chronic, progressive and irreversible disease, early detection and treatment of glaucoma are essential for a good visual prognosis. One of the greatest challenges in diagnosing the disease comes from its asymptomatic nature until the glaucomatous process reaches an advanced stage. Thus, glaucoma diagnosis is often performed as case finding in regular ophthalmic consultations. In developing countries, detecting glaucoma becomes even a more complicated issue due to the limited access to Ophthalmic eye care facilities by large part of the population. However, it is clear that if we want to reduce the burden of blindness due to glaucoma, we must improve the detection of the disease.

There are two approaches to detect patients that are unaware of their glaucoma: either make the existing system work better by improving opportunistic case finding, or change the system by initiating a systematic population screening program ${ }^{(7)}$. In addition, the health care system needs to ensure enough capacity to handle the newly detected cases. Recent studies have shown that up to the current time and with currently available diagnostic techniques, there is not enough evidence to support the cost-effectiveness of a systematic population screening program, even in developed countries ${ }^{(8)}$.

In Brazil, there is a reasonable public health program to detect and treat systemic arterial hypertension and diabetes, which includes free distribution of some medications. Unfortunately glaucoma detection may not be as straightforward as diagnosing systemic hypertension or diabetes. These diseases are relatively

\footnotetext{
Submitted for publication: May 11, 2011

Accepted for publication: May 11, 2011

1 Physician, Department of Ophthalmology, Universidade Federal de São Paulo - UNIFESP - São Paulo (SP), Brazil.

2 Physician, Deparment of Ophthalmology, Universidade Federal do Paraná - UFPR-Curitiba (PR), Brazil.

3 Physician, Hamilton Glaucoma Center, Department of Ophthalmology, University of California San

Diego, La Jolla, CA.
}

Funding: No specific financial support was available for this study.

Disclosure of potential conflicts of interest: M.T.Leite, None; L.M.Sakata, None; F.A.Medeiros, Consultant (Alcon Laboratories, Allergan, Pfizer), Financial Support (Alcon Laboratories, Carl Zeiss Meditec, Pfizer, Merck, Sensimed), Recipient (Alcon Laboratories, Allergan, Carl Zeiss Meditec Meditec, Pfizer, Merck, Sensimed),
Pfizer, Reichert, Merck, Sensimed).

Correspondence address: Mauro Toledo Leite. Rua Borges Lagoa, 783/32 - São Paulo - SP 04038-031 - Brazil - E-mail: mauro66@uol.com.br 
easier to diagnose, as their main biological variable measurements (arterial blood pressure and glycemia, respectively) can be evaluated in an objective manner by non-expensive and easy to interpret tests. On the other hand, glaucoma diagnosis can be quite challenging. It is often necessary to perform multiple exams that require highly trained professionals to interpret their results, and many parts of the diagnostic criteria can be considered subjective. Thus, since the availability of resources is limited, it is likely that the best option at the current time would be to try to improve the awareness of the disease among the general population, including education about risk factors such as positive family history. Additionally, a better medical education could also optimize opportunistic case finding.

\section{GLAUCOMA TREATMENT}

The ultimate goal of glaucoma treatment is to slow down disease progression to a rate in which the patient will not experience a vision-related decrease in quality of life. Glaucoma treatment in developing countries should consider clinical, laser, and surgical approaches.

Glaucoma medications do not improve vision, may have important side effects and are relatively expensive. Thus, compliance can be a major issue, which is related to level of education and socio-economic status of the patient ${ }^{(9)}$. In a recent study conducted in Brazil, 21.5\% of the patients revealed non-adherence to treatment $t^{(10)}$. Currently, some centers are receiving government support in Brazil to provide medications for glaucoma patients at no cost. We eagerly hope this support to be extended to as many other centers as possible. However, as the resources are limited, it is important to ensure that treatment is directed towards those patients at risk for developing functional disability from the disease. It is important to emphasize that there is not only under diagnosis but also over diagnosis of glaucoma, as up to 50\% of the patients treated for glaucoma actually do not have the disease ${ }^{(11)}$. Good quality diagnostic assessment and proper allocation of resources are therefore essential.

Another requirement for successful medical treatment is adequate longitudinal follow-up through periodic visits with the attending ophthalmologist. In developing countries, ophthalmology centers are usually concentrated in urban areas; therefore, people in rural areas may have to travel several hours in order to obtain medical assistance and this may impair proper care. In fact, a study conducted in Ghana showed that the chance of developing blindness from glaucoma was much higher in rural areas compared to urban areas $^{(12)}$. Therefore, investments in proper Ophthalmic care need to tackle this issue, not only for glaucoma but also all other ophthalmic diseases.

It has been advocated by some that primary surgery would be a good option for glaucoma treatment in the developing world, because it is a "one shot" solution if well-performed. In India, for example, surgery is often used as first line treatment ${ }^{(13)}$. However, the procedure is not curative as opposed to cataract surgery, requires long-term post-operative care, and may be prone to severe complications. The problematic access to medical care in developing countries makes the management of surgical complications a challenge and it may represent another potential source of blindness. Laser trabeculoplasty might be an interesting option as primary treatment; however, its efficacy is limited in the level of intraocular pressure reduction and in the duration of the effect ${ }^{(14-15)}$.

\section{CONCLUSION}

There is a strong need to increase the quantity and quality of population-based epidemiologic studies of the prevalence of glaucoma and burden of the disease in Brazil and other developing countries. Such studies are essential in order to enable the development of adequate strategies to deal with the problem. Current strategies to improve detection of disease should aim at increasing awareness of the disease among the general population and knowledge of risk factors, such as positive family history. Additionally, educational programs should be designed to improve recognition of the signs of the disease by ophthalmologists and other medical professionals. Treatment resources should be allocated to those patients at highest risk of developing functional impairment from the disease and the therapy of choice should take into account efficacy, adherence to treatment and potential side effects.

\section{REFERENCES}

1. Quigley HA, Broman AT. The number of people with glaucoma worldwide in 2010 and 2020. Br J Ophthalmol. 2006;90(3):262-7. Comment in: Brit J Ophthalmol. 2006;90(3):253-4.

2. Sakata K, Sakata LM, Sakata VM, Santini C, Hopker LM, Bernardes R, et al. Prevalence of glaucoma in a South brazilian population: Projeto Glaucoma. Invest Ophthalmol Vis Sci. 2007:48(11):4974-9.

3. Tielsch JM, Sommer A, Katz J, Royall RM, Quigley HA, Javitt J. Racial variations in the prevalence of primary open-angle glaucoma. The Baltimore Eye Survey. JAMA. 1991;266(3): 369-74. Comment in: JAMA. 1991;266(3):410.

4. Sommer A, Tielsch JM, Katz J, Quigley HA, Gottsch JD, Javitt JC, et al. Racial differences in the cause-specific prevalence of blindness in east Baltimore. N Engl J Med. 1991; 325(20):1412-7. Comment in: N Engl J Med. 1991;325(20):1440-2.

5. Coffey M, Reidy A, Wormald R, Xian WX, Wright L, Courtney P. Prevalence of glaucoma in the west of Ireland. Br J Ophthalmol. 1993;77(1):17-21.

6. United Nations Population Division. Department of Economic and Social Affairs. Population Division. World Population Prospects: The 2008 Revision [Internet]. New York: UNPD; 2009. [cited 2011 Jan 25]. Available from: http://data.un.org/Explorer.aspx?d=PopDiv

7. Tuulonen A. Cost-effectiveness of screening for open angle glaucoma in developed countries. Indian J Ophthalmol.2011;59 Suppl:S24-30.

8. Burr JM, Mowatt G, Hernandez R, Siddiqui MA, Cook J, Lourenco T, et al. The clinical effectiveness and cost-effectiveness of screening for open angle glaucoma: a systematic review and economic evaluation. Health Technol Assess. 2007:11(41):iii-iv, ix-x, 1-190.

9. Friedman DS, Okeke CO, Jampel HD, Ying GS, Plyler RJ, Jiang Y, et al. Risk factors for poor adherence to eyedrops in electronically monitored patients with glaucoma. Ophthalmology. 2009;116(6):1097-105.

10. Castro AN, Mesquita WA. [Noncompliance with drug therapy for glaucoma]. Arq Bras Oftalmol. 2008;71(2):207-14. Portuguese

11. Vaahtoranta-Lehtonen $H$, Tuulonen $A$, Aronen $P$, Sintonen $H$, Suoranta L, Kovanen $N$, et al. Cost effectiveness and cost utility of an organized screening programme for glaucoma. Acta Ophthalmol Scand. 2007;85(5):508-18.

12. Ntim-Amponsah CT. Visual loss in urban and rural chronic glaucoma patients in Ghana. Trop Doct. 2002;32(2):102-4. Comment in: Trop Doct. 2002;32(2):65.

13. Thomas R, Paul P, Muliyil J. Glaucoma in India. J Glaucoma. 2003;12(1):81-7.

14. Fink Al, Jordan AJ, Lao PN, Fong DA. Therapeutic limitations of argon laser trabeculoplasty. Br J Ophthalmol. 1988;72(4):263-9.

15. Juzych MS, Chopra V, Banitt MR, Hughes BA, Kim C, Goulas MT, et al. Comparison of longterm outcomes of selective laser trabeculoplasty versus argon laser trabeculoplasty in open-angle glaucoma. Ophthalmology. 2004;111(10):1853-9. 